\title{
Possibilidade de Uso de Mecanismos de Compensação para a Regularização Fundiária de Unidades de Conservação Estaduais em Minas Gerais
}

\author{
Fernanda Teixeira Silva ${ }^{1} \&$ Ana Paula Leite Prates ${ }^{2}$
}

Recebido em 25/10/2019 - Aceito em 30/03/2020

1 Instituto Estadual de Florestas - IEF/MG, Minas Gerais/MG, Brasil. <teixeirasilvfernanda@gmail.com>.

2 Ministério de Meio Ambiente, Professora do Mestrado e Doutorado Profissionais em Biodiversidade em Unidades de Conservação EBT/JBRJ, Brasília/DF, Brasil. CEP: 70.774-070. <anaplprates@gmail.com>

\begin{abstract}
RESUMO - As unidades de conservação são consideradas um dos principais instrumentos para a conservação da biodiversidade. Entretanto, uma das maiores pendências de efetividade dessas áreas diz respeito às questões de regularização fundiária, tanto na esfera federal como estadual, padrão observado também no estado de Minas Gerais. Nesse contexto, o objetivo deste estudo foi analisar a utilização de quatro mecanismos de compensação ambiental que possuem interface com o ordenamento territorial de áreas protegidas, por meio de levantamento documental e legislativo. Também foram analisadas as perspectivas da utilização desses instrumentos para a regularização fundiária de unidades de conservação estaduais de domínio público pelo Instituto Estadual de Florestas (IEF), autarquia responsável pela gestão dessas áreas no estado de Minas Gerais, concluindo-se pelo papel promissor da compensação referente aos empreendimentos minerários para a regularização fundiária e implantação das unidades de conservação estaduais.
\end{abstract}

Palavras-chave: Biodiversidade; compensação ambiental; regularização fundiária; unidades de conservação; Minas Gerais.

\section{Possibility of Using Compensation Mechanisms for Land Regularization of State Conservation Units in Minas Gerais}

\begin{abstract}
Protected areas are considered one of the main instruments for biodiversity conservation. However, one of the greatest pending effectiveness in these areas concerns land regularization issues, both at the federal and state levels, pattern also observed in the state of Minas Gerais. The aim of this study was to approach four environmental compensation mechanisms that have interface with the spatial planning of protected areas in the public domain, through documentary and legislative survey. Are also analyzed the prospects of using these instruments for land regularization state protected areas in the public domain by the Instituto Estadual de Florestas - IEF (State Forestry Institute - IEF), governmental agency responsible for management of state protected areas in Minas Gerais State, concluding that the mining compensation is promising for the land regularization and implantation of state conservation units.
\end{abstract}

Keywords: Biodiversity; enviroment recovery fee; protected areas; land regularization; Minas Gerais.

\section{Posibilidad de Utilizar Mecanismos de Compensación para la Regularización de la Tierra de las Unidades Estatales de Conservación en Minas Gerais}

RESUMEN - Las áreas protegidas se consideran uno de los principales instrumentos para la conservación de la biodiversidad. Sin embargo, una de las mayores pendientes de efectividad de estas áreas se refiere a los problemas de regularización de tierras, tanto a nivel federal como estatal, también observado en el estado de Minas Gerais. En este contexto, el objetivo de este estudio es abordar el uso de cuatro mecanismos de compensación ambiental que interactúan con la planificación territorial de 
áreas protegidas en el dominio público, a través de la investigación documental y legislativa. También se analizan las perspectivas del uso de estos instrumentos para la regularización de las áreas protegidas estatales por parte del IEF, responsable de la gestión de las unidades de conservación estatales en Minas Gerais, concluyendo que la compensación minera es prometedora para la regularización de la tierra y el establecimiento de unidades estatales de conservación.

Palabras clave: Biodiversidad; compensación ambiental; dominio público; regularización de tierras; áreas protegidas; Minas Gerais.

\section{Introdução}

A importância das áreas protegidas para a proteção da diversidade biológica e dos recursos genéticos associados, assim como os benefícios advindos dessas áreas, é enfatizada por diversos autores, dentre eles: Pimm et al. (2001), WWFBrasil (2008), Leuzinger (2013), Stolton \& Dudley (2010) e Butchart et al. (2012).

É inegável o papel das áreas protegidas na conservação da biodiversidade, as quais podem funcionar em conjunto, como elementos integradores da paisagem, refletindo diretamente na conservação da biodiversidade, preservação da natureza, uso sustentável dos recursos naturais, restauração e recuperação dos ecossistemas, e provisão de importantes serviços ecossistêmicos.

Verifica-se que, para além da sua significativa importância na preservação dos bens naturais $e$ promoção da qualidade de vida da sociedade, a criação e implementação dessas áreas devem ser vistas também como uma ferramenta indispensável ao cumprimento dos compromissos constitucionais internos $e$ ao dos vários acordos internacionais firmados pelo Brasil (WWF-Brasil 2008).

Antunes (2013) ressalta que existem diversos tratados e convenções internacionais e bilaterais sobre a proteção da diversidade biológica, sendo o Brasil signatário de muitos deles. Todos esses tratados e convenções se relacionam a grandes desafios da humanidade com relação à crise ambiental atualmente instalada, em especial aqueles relativos à perda da diversidade biológica, à escassez de água potável e ao aquecimento global.

Entre esses tratados, destacam-se a Convenção da Diversidade Biológica (CDB), a Convenção de Áreas Úmidas (Ramsar) e a Convenção-Quadro das Nações Unidas sobre Mudança do Clima. Os princípios dessas
Convenções estão previstos em algumas das mais importantes políticas, normas legais $e$ documentos nacionais referentes à conservação da biodiversidade e das áreas protegidas, entre os quais se destacam a Política Nacional de Meio Ambiente (Brasil 1981), a lei que instituiu o Sistema Nacional de Unidades de Conservação da Natureza (SNUC) (Brasil 2000), a Política Nacional de Biodiversidade (Brasil 2002a) e o Plano Estratégico Nacional de Áreas Protegidas (PNAP) (Brasil 2006a), além de estarem assegurados pela Constituição Federal (Brasil 1988).

O SNUC, instituído pela Lei Federal n 9.985 , de 18 de julho de 2000, traz a definição de critérios e normas para o estabelecimento e a gestão dessas áreas, no âmbito federal, estadual ou municipal, além da indicação de fontes de financiamento para a implantação e criação das unidades de conservação (UCs) (Brasil 2000).

As UCs são divididas em dois grupos: o de proteção integral e o de uso sustentável, os quais possuem categorias com características distintas. De acordo com Prates \& Sousa (2014), as UCs dispostas em categorias diferentes atuam de forma complementar, contribuindo para a conservação dos recursos naturais. Cada uma das categorias de UC previstas no SNUC se diferencia quanto à forma de proteção $e$ aos usos permitidos, $e$ esses aspectos, combinados, possibilitam que as diversas ações voltadas à conservação ambiental convirjam para um objetivo comum.

Conforme Oliveira (2010), a titularidade das áreas não é determinada pelo grupo ao qual as UCs pertencem, tendo em vista que existem UCs de uso sustentável que demandam o domínio público, assim como existem UCs de proteção integral nas quais é facultada a propriedade privada. Dentre as categorias de UC cujas áreas devem ser de domínio público estão parques nacionais, estações ecológicas, reservas biológicas, florestas nacionais, reservas de fauna, reservas extrativistas e reservas 
de desenvolvimento sustentável. Em alguns desses casos, além do domínio, também a posse da área deve ser pública.

Kury (2009) afirma que a regularização fundiária pode ser visualizada como um mecanismo de vital importância para as justiças ambiental e social, na medida em que prioriza a proteção da natureza sem deixar em segundo plano o direito de propriedade do particular.

Além disso, a regularização fundiária tem sido apontada como um dos pilares para uma gestão mais eficaz que impacta direta e positivamente na conservação da biodiversidade associada a essas UCs de domínio público.

Em concordância com a necessidade de melhorias no desenvolvimento do processo de regularização fundiária $e$ a busca por alternativas para a resolução dessa questão tão complexa, torna-se importante a análise e a utilização de mecanismos legais de compensação que possuem interface com a regularização fundiária de UCs de domínio público.

Este estudo foca especificamente o caso das UCs estaduais de Minas Gerais, sendo objeto de análise a compensação por significativo impacto ambiental (Brasil 2000, Brasil 2002b e Brasil 2009), a compensação pelo corte ou supressão de vegetação nativa do bioma da Mata Atlântica (Brasil 2006b e Brasil 2008), a compensação por empreendimentos minerários (Minas Gerais 2013) e a compensação de reserva legal (Brasil 2012 e Minas Gerais 2013).

\section{Metodologia}

Para o desenvolvimento deste estudo, foi realizada uma análise de quatro instrumentos legais de compensação (compensação ambiental, compensação por corte ou supressão de vegetação do bioma Mata Atlântica, compensação por empreendimentos minerários e compensação de reserva legal) relacionados com a regularização fundiária de UCs, utilizados pelo Instituto Estadual de Florestas (EF/MG). Também foram verificadas as possibilidades de avanço nesse sentido.

Este estudo também se baseou em uma análise documental e legislativa dessas diferentes compensações, assim como na regularização fundiária de UC, objetivando avaliar o status relativo ao tema em Minas Gerais.
O levantamento bibliográfico e legislativo fundamentou a compreensão $e$ o posicionamento sobre o tema da compensação e regularização fundiária de UCs de domínio público, tendo sido realizada uma busca em diversas fontes, como, por exemplo: banco de teses da Capes, Google Acadêmico, revistas científicas afetas ao tema, Imprensa Oficial do Governo do Estado de Minas Gerais, documentação disponível na Secretaria de Estado de Meio Ambiente e Desenvolvimento Sustentável de Minas Gerais (Semad) e demais setores responsáveis no IEF.

De forma a obter um panorama das UCs administradas pelo IEF, foi feito um levantamento, na Gerência de Criação de Unidades de Conservação do Instituto, de informações gerais sobre as categorias de UCs estaduais criadas (denominação e área total das UCs, em hectares). Após a obtenção dos dados gerais sobre todas as UCs estaduais, foi feita uma separação das UCs de domínio público, assim como das categorias de UCs que podem ensejar ações de regularização fundiária.

Para traçar um cenário sobre a situação das UCs estaduais no que se refere à regularização fundiária, foram obtidas informações com a Gerência de Regularização Fundiária (GEREF) do IEF e por meio do Diagnóstico elaborado por IEF e Semad (finalizado em 2014), a respeito das pendências de regularização fundiária.

A partir dos dados e informações levantados, foi realizada uma análise da utilização dos quatro mecanismos de compensação ambiental e das perspectivas de utilização desses instrumentos para a regularização fundiária de UCs estaduais de domínio público pelo IEF.

\section{A Necessidade de Regularização Fundiária}

A consolidação territorial de uma UC é um dos grandes desafios para a implantação $e$ gestão dessas áreas, e contempla um conjunto de ações com o objetivo de permitir a efetiva governabilidade do território das UCs, incluindo: a consolidação de limites, o reassentamento de populações residentes, a mediação de conflitos socioambientais, a incorporação de terras públicas e o estabelecimento de termos de compromisso com populações residentes em UCs de posse e domínio públicos (Szabo et al. 2011). 
A complexidade e desarticulação do processo de regularização fundiária e a forma fragmentada na qual os procedimentos são armazenados, além das lacunas ainda existentes na legislação sobre o assunto, contribuíram para que não tenham sido verificados grandes avanços no ordenamento territorial dessas áreas protegidas.

Diversos são os autores (Guatura et al. 1996, Pádua 2004, Brandão et al. 2010) que apontam a herança cultural e política brasileira como responsável pela desordem fundiária secular que assola o país, da qual também são vítimas as UCs, trazendo como uma das principais consequências a dificuldade de identificação do domínio das áreas.

O conjunto de fatores apresentados é responsável pelo acúmulo de um passivo de áreas a serem regularizadas, aumentando sobremaneira os conflitos relacionados à instituição das UCs de domínio público.

Prates \& Sousa (2014) destacam a existência de um passivo significativo de áreas a serem regularizadas nas unidades de conservação federais, nos diferentes biomas do país, com cerca de 10 milhões de hectares de áreas privadas que ainda precisam ser desapropriadas. No âmbito de Minas Gerais, também pode ser observada situação semelhante, com a existência de grande passivo relacionado à regularização fundiária das áreas protegidas.

Refletindo a relevância da regularização fundiária para a conservação da biodiversidade em UCs, Nolte et al. (2013), a partir da utilização do método Rapid Assessment and Priorization of Protected Area Management (RAPPAM), encontrou o seguinte resultado para as áreas protegidas da região da Amazônia: a ausência de conflitos de posse da terra é consistentemente associada ao sucesso na redução de pressões de desmatamento, ofuscando diversos outros fatores (orçamento, pessoal, plano de manejo e outros) em termos de relevância, o que aponta para a importância de resolver a questão da posse da terra na gestão de áreas protegidas.

Apesar disso, verifica-se que a regularização fundiária tem sido tratada com baixo grau de prioridade, conforme apontado no estudo de Rocha et al. (2010), no qual, a partir de um diagnóstico da situação fundiária dos parques nacionais brasileiros, observou não haver uma relação positiva entre as datas de criação dos parques nacionais $e$ as suas respectivas situações de regularização fundiária.

\section{Interface entre Mecanismos de Compensação e Regularização Fundiária}

Não resta dúvida de que os instrumentos administrativos e jurídicos, a exemplo dos mecanismos de compensação, podem acelerar o processo de regularização fundiária das unidades de conservação.

Compensar, em linhas gerais, significa oferecer uma alternativa igual ou maior, para uma forma de uso ou lesão (evitável ou inevitável) de um bem de qualquer natureza, que, por isso, deve ser substituído por outro, a fim de remover ou minimizar o dano verificado. No caso da compensação ambiental, requer-se, normalmente, que o uso ou o dano sejam inevitáveis ou se façam necessários em vista de um benefício maior e em função do interesse social (Milaré 2014).

Nesse sentido, quando a reparação natural for impossível ou desproporcional, deve-se lançar mão dos mecanismos de compensação ecológica, substituindo o bem ambiental lesado por outro equivalente, ou aplicando-se a sanção monetária com o mesmo fim de substituição (Costa 2008).

\section{Reparação do Dano e o Estabelecimento de Condicionantes nos Processos de Licenciamento Ambiental}

Osdanosambientais podem ser classificados como reparáveis, mitigáveis ou compensáveis, conforme descrição a seguir: "Reparáveis são aqueles danos que, dadas as suas dimensões, não ostentam um caráter de irreversibilidade; já os mitigáveis são aqueles que, mediante a intervenção humana, podem ser reduzidos a níveis desprezíveis, haja vista que intervenções técnicas adequadas são suficientes para mantê-los sob adequado controle. Compensáveis são os danos ambientais que, consideradas suas dimensões $e$ características peculiares, não podem ser reparados ou mitigados, muito embora, quando sopesados com os benefícios que a intervenção venha a ocasionar, se justifiquem ante os termos do artigo $2^{\circ}$ da Lei da Política Nacional de Meio Ambiente" (Antunes 2013).

Bechara (2011) afirma, de forma bastante adequada, que "a compensação não pretende 
vender um direito de poluir", mas, sim, contrabalançar as perdas ambientais atreladas às atividades poluidoras licenciadas, estando associada, no Direito, a um dano.

A reparação do dano através dos mecanismos de compensação pode ocorrer de duas formas: por meio da reparação in natura ou da reparação in pecunia (pagamento em dinheiro) (Bechara 2007).

\section{Compensação por Significativo Impacto Ambiental (Lei Federal no 9.985/2000)}

Atualmente, a compensação por significativo impacto ambiental é disciplinada pelo art. 36 da Lei Federal n 9.985/2000, que trouxe a obrigatoriedade, aos empreendimentos considerados como causadores de significativos impactos ambientais, de apoiar a implantação e manutenção de unidades de conservação de proteção integral.

Pinto (2012) afirma que não é necessária a comprovação do dano consumado para que se faça possível a exigência da compensação ambiental, bastando que o empreendimento ou a atividade sejam caracterizados como potencialmente causadores de significativo impacto ambiental pelo órgão ambiental licenciador. Dessa forma, pode ser definida como compensação por dano futuro.

O Decreto Federal n 4.340/2002 determinou, em seu art. 33, as prioridades de aplicação dos recursos da compensação: I - regularização fundiária e demarcação das terras; II - elaboração, revisão ou implantação de plano de manejo; III - aquisição de bens e serviços necessários à implantação, gestão, monitoramento e proteção da unidade, compreendendo sua área de amortecimento; $I V$ - desenvolvimento de estudos necessários à criação de nova unidade de conservação; $e$ $\mathrm{V}$ - desenvolvimento de pesquisas necessárias para o manejo da unidade de conservação e área de amortecimento (Brasil 2002b).

É possível perceber a importância dada pelo legislador à resolução da questão fundiária das UCs de domínio público, tendo em vista o seu estabelecimento como a prioridade de utilização dos recursos arrecadados a título de compensação.
Após inúmeras discussões sobre o tema, foi elaborado e publicado o Decreto Federal $\mathrm{n}^{\circ}$ 6.848/2009, que alterou o Decreto Federal $\mathrm{n}^{\circ} 4.340 / 2002$, fixando o grau de impacto nos ecossistemas em percentuais que variam de $0 \%$ a $0,5 \%$ e, portanto, estabelecendo um percentual máximo para essa medida compensatória (Brasil 2009).

Em Minas Gerais, a compensação ambiental é regulamentada pelo Decreto Estadual $n^{\circ} 45.175 / 2009$, alterado pelo Decreto Estadual $\mathrm{n}^{\circ} 45.629 / 2011$. O art. 10 do Decreto Estadual $n^{\circ} 45.629 / 2011$ estabelece que os impactos ambientais de empreendimentos sujeitos à compensação deverão ser identificados com base nos estudos ambientais solicitados pelo órgão ambiental, inclusive e, se for o caso, no Estudo de Impacto Ambiental e no Relatório de Impacto Ambiental (EIA/RIMA) (Minas Gerais 2011).

Com relação às formas de cumprimento da compensação ambiental, os arts. 14 e 15 do Decreto Estadual no 45.629/2011 definem, respectivamente, a possibilidade de depósito de recursos financeiros em conta específica do órgão gestor das UCs beneficiadas ou, alternativamente, dação em pagamento de imóvel localizado no interior de UC pendente de regularização fundiária, cabendo, neste último caso, a avaliação do imóvel pela Secretaria de Estado de Planejamento e Gestão (SEPLAG).

O estabelecimento da condicionante de compensação ambiental em Minas Gerais é feito no momento do licenciamento ambiental dos empreendimentos causadores de significativos impactos ambientais, pelas Superintendências Regionais de Meio Ambiente (SUPRAMs), mediante aprovação pelas Unidades Regionais Colegiadas (URCs). Já a análise dos processos de compensação ambiental é feita pelo IEF, por meio da Gerência de Compensação Ambiental (GCA), mediante a apresentação, pelos empreendedores, de toda a documentação listada na Portaria IEF $n^{\circ} 55 / 2012$, a qual estabelece os procedimentos para a formalização dos processos de compensação ambiental (IEF 2012).

A análise e a definição da compensação, assim como a recomendação da distribuição de recursos (inclusive para as UCs afetadas), são feitas por meio da verificação do valor de referência dos empreendimentos, informado obrigatoriamente pelo empreendedor; da aferição 
do Grau de Impacto (GI), fundamentado nos estudos ambientais apresentados, no Parecer Único, emitido no âmbito do licenciamento, bem como na literatura especializada; $e$ na verificação da afetação de UC pelo empreendimento.

A distribuição dos recursos é realizada observando-se a apuração do percentual destinado a cada UC afetada, por meio de três matrizes de avaliação da relevância dessas áreas protegidas, classificando-as de acordo com sua importância biológica e biofísica: Matriz 1 - Categoria de Importância Biológica x Status de Conservação de Espécies; Matriz 2 - Fator Biológico x Fator Físico; e Matriz 3 - Fator Biofísico x Categoria de Manejo da UC (IEF 2018).

O Parecer Único, elaborado pelo IEF, deve ser submetido à análise e aprovação da Câmara de Proteção à Biodiversidade e Áreas Protegidas (CPB) do Conselho Estadual de Política Ambiental, conforme disposto no inciso XIII do art. 13 do Decreto Estadual n ${ }^{\circ} 46.953$, de 23 de fevereiro de 2016, alterado pelo Decreto Estadual no 47.565, de 19 de dezembro de 2018, que estabelece como competência da CPB fixar o valor e aprovar a destinação e a aplicação da compensação ambiental (Minas Gerais 2016).

No ano de 2015, durante a $164^{a}$ Reunião Ordinária do Plenário do Conselho Estadual de Política Ambiental (Copam), foram apresentados dados sobre essa compensação, pela Gerência de Compensação Ambiental do IEF. Na reunião informou-se sobre a existência de um saldo financeiro de, aproximadamente, $\mathrm{R} \$ 200$ milhões em junho de 2015. Além disso, foi mostrado um comparativo entre as receitas oriundas dessa compensação $e$ as despesas realizadas com a utilização desses recursos no período de 2007 a 2015. O Gráfico 1, a seguir, demonstra um aumento progressivo na arrecadação de recursos relativos à compensação ambiental nos anos de 2009 a 2013, com elevação expressiva no total de recursos arrecadados nos anos de 2011 a 2014 (receita contabilizada). Por outro lado, ainda conforme o Gráfico 1, o período de 2011 a 2014 foi o que apresentou a menor utilização de recursos (valor pago), proporcionalmente à quantia de recursos arrecadados (IEF 2015a).

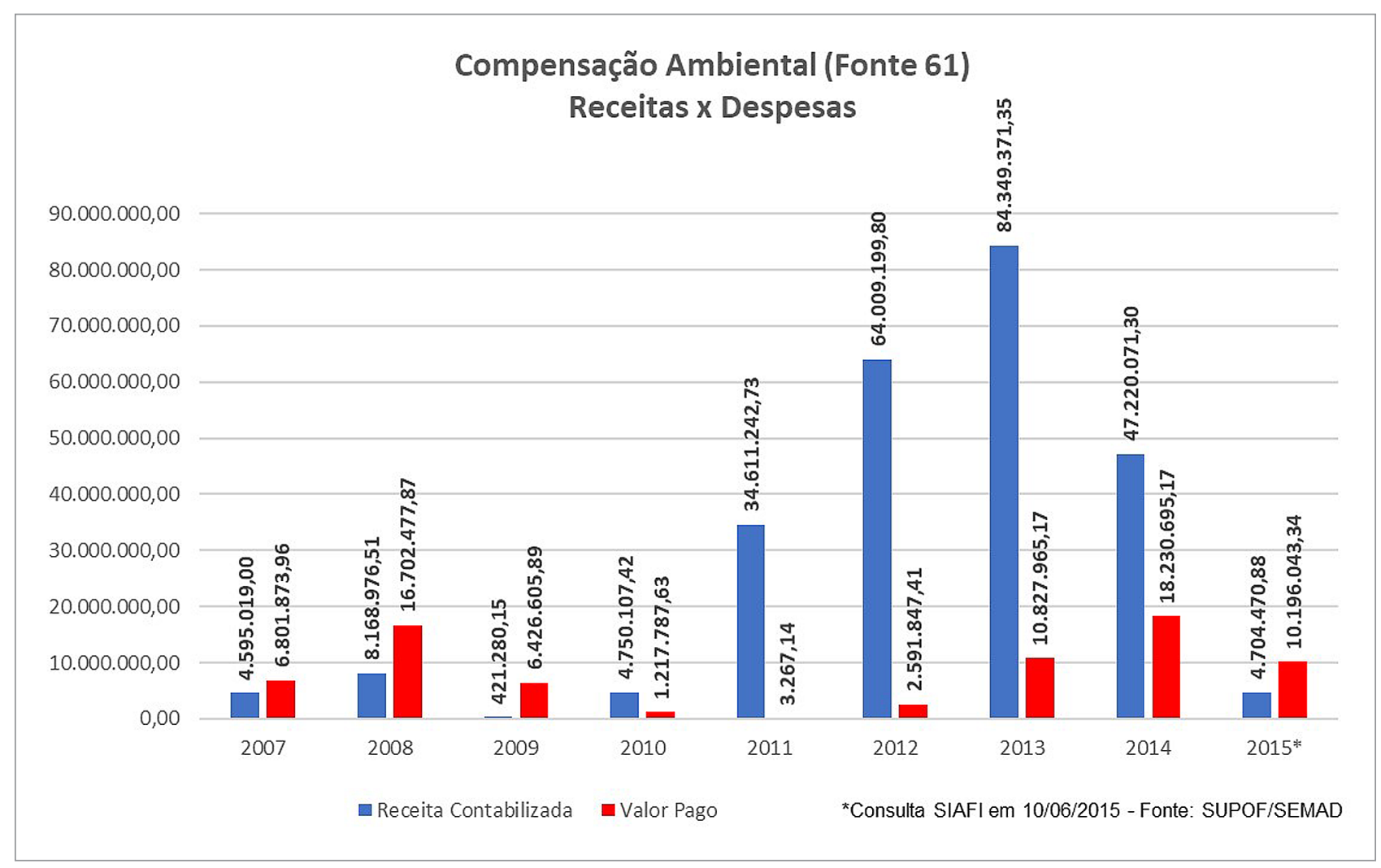

Gráfico 1 - Receitas e despesas de compensação por significativo impacto ambiental (de 2007 a junho/2015). Fonte: Apresentação "Compensação Ambiental e Florestal", realizada na $164^{a}$ Reunião Ordinária do plenário do Copam em 15/07/2015 (IEF 2015a). 
O Gráfico 2 permite visualizar a utilização dos recursos dessa compensação por tipo de atividade. Para fins de visualização dos gastos, efetuou-se a separação dos recursos investidos em bens e serviços daqueles investidos na elaboração de planos de manejo, e dos relacionados à prevenção $e$ ao combate a incêndios florestais.
Observa-se que a maior parte dos recursos foi utilizada para o custeio de bens e serviços, seguido pelo custeio de ações de regularização fundiária de unidades de conservação, em escala consideravelmente menor. Importante destacar que os gastos com bens e serviços representam mais de $90 \%$ do valor total utilizado.

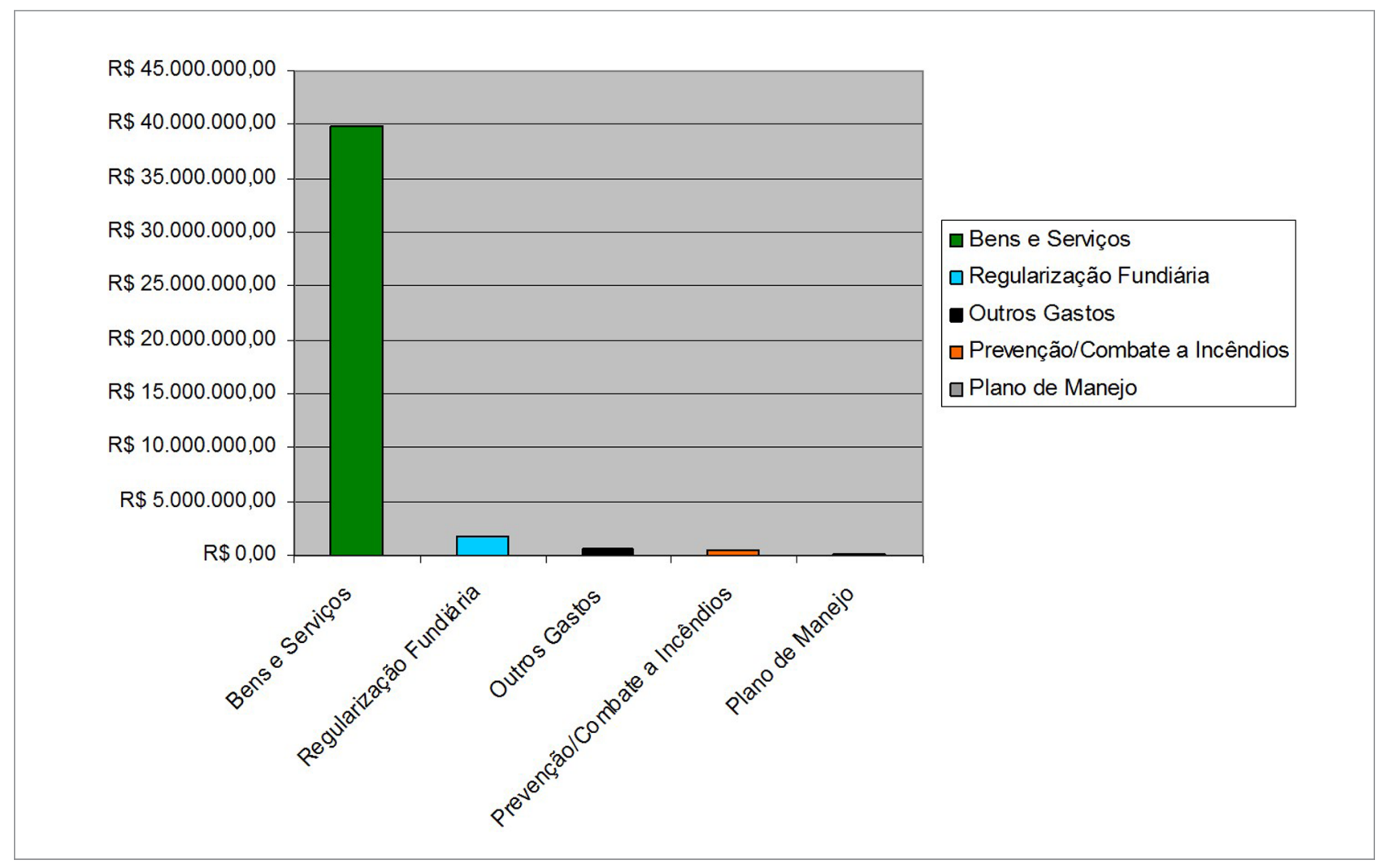

Gráfico 2 - Utilização de recursos de compensação ambiental no período de 2010 a 2015. Fonte: Baseado na apresentação "Compensação Ambiental e Florestal", realizada na 164a Reunião Ordinária do plenário do Copam em 15/07/2015 (IEF 2015a).

Ao analisar os dados levantados, nota-se uma tendência de utilização dos recursos da compensação ambiental para atividades de custeio das unidades de conservação estaduais (bens e serviços), o que inclui a contratação de empresas para a prestação de serviços contínuos às UCs.

\section{Compensação pelo Corte ou pela Supressão de Vegetação Nativa do Bioma Mata Atlântica (Lei Federal $n^{0}$ 11.428/2006)}

O bioma Mata Atlântica está extremamente reduzido e fragmentado, tendo sua área original de $1.290 .692,46 \mathrm{~km}^{2}$ (aproximadamente 15\% do território brasileiro) reduzida a $95.000 \mathrm{~km}^{2}$, cerca de $7 \%$ da área original (Fundação SOS Mata Atlântica \& Instituto Nacional de Pesquisas Espaciais 2009). Ainda conforme informações da SOS Mata Atlântica, tem havido uma redução no desmatamento do bioma em Minas Gerais nos últimos anos, como pode ser visualizado na Tabela 1. No entanto, há muito o que se fazer para reduzir ainda mais esses números.

A Tabela 1 (a seguir), que compreende o período de 2011 a 2018, apresenta: a "Área total do bioma Mata Atlântica em MG" (Mapeamento da Lei Federal $\left.n^{\circ} 11.428 / 2006\right)$, considerando a área original do bioma, independentemente da 
existência ou não de cobertura vegetal nativa atualmente; a "Área de cobertura vegetal nativa desmatada (ha)"; e a "Área com cobertura vegetal nativa remanescente (ha)", considerando tanto a perda como a regeneração de vegetação nativa na área de abrangência do bioma no estado. Além disso, é feito um comparativo do desmatamento anual, com quantificação percentual acerca da redução ou do aumento do desmatamento, quando comparado com o ano anterior ("Alteração do desmatamento em relação ao período anterior"). Conforme informações da SOS Mata Atlântica, os desmatamentos cujas imagens não fornecem um bom grau de confiança e todos os desmatamentos com menos de 3ha são classificados como "indício de desmatamento", não havendo divulgação desses dados, que são utilizados como referência para uma nova observação no próximo período.

Tabela 1 - Dados do desmatamento no bioma Mata Atlântica em Minas Gerais, no período de 2011 a 2018.

\begin{tabular}{|c|c|c|c|c|}
\hline & & Hectares (ha) & & $\%$ \\
\hline & Área total MG & 58.651 .979 & & 100 \\
\hline & $\begin{array}{c}\text { Área total do bioma } \\
\text { Mata Atlântica } \\
\text { em MG } \\
\text { (Lei no } 11.428 / 2006)\end{array}$ & 27.622 .623 & & 47 \\
\hline & Período & $\begin{array}{c}\text { Área de cobertura } \\
\text { vegetal nativa } \\
\text { desmatada (ha) }\end{array}$ & $\begin{array}{l}\text { Área com cobertura } \\
\text { vegetal nativa } \\
\text { remanescente (ha) }\end{array}$ & $\begin{array}{c}\text { Alteração do } \\
\text { desmatamento em } \\
\text { relação ao período } \\
\text { anterior (\%) }\end{array}$ \\
\hline & 2011-12 & 10.752 & 2.869 .256 & ----- \\
\hline \multicolumn{5}{|l|}{ Alteração anual } \\
\hline & $2012-13$ & 8.437 & 2.864 .487 & $-21,53$ \\
\hline & 2013-14 & 5.608 & 2.858 .654 & $-33,53$ \\
\hline & $2014-15$ & 7.702 & 2.841 .728 & 37,34 \\
\hline & $2015-16$ & 7.410 & 2.836 .004 & $-3,79$ \\
\hline & $2016-17$ & 3.128 & 2.828 .890 & $-57,79$ \\
\hline & 2017-18 & 3.379 & 2.829 .026 & 8,02 \\
\hline
\end{tabular}

Fonte: Baseado em Fundação SOS Mata Atlântica \& Instituto Nacional de Pesquisas Espaciais (2013, 2014, 2015, 2016, 2017, 2018, 2019).

Atualmente, a utilização e a proteção da biodiversidade nativa desse bioma são disciplinadas pela Lei Federal $n^{\circ} 11.428 / 2006$. A lei não proíbe definitivamente o corte de vegetação ou a ocupação de áreas, mas cria regras rígidas para tanto, estabelecendo critérios diferenciados para o corte e a supressão de vegetação nativa dependendo do estágio de conservação da área a ser suprimida (Brasil 2006b).

O Decreto Federal $n^{\circ}$ 6.660/2008 define os tipos de vegetação protegidos pela Lei da
Mata Atlântica, estabelecendo que o mapa do bioma Mata Atlântica contempla a configuração original, as formações florestais nativas e os ecossistemas associados. Estabelece, ainda, disjunções nos biomas Caatinga e Cerrado, que são as formações florestais nativas que devem receber o mesmo tratamento jurídico dado à Mata Atlântica pela Lei Federal, fora da sua área de aplicação (Brasil 2008).

A todo aquele que suprimir vegetação primária ou secundária em estágio médio $e$ 
avançado de regeneração pertencente ao bioma Mata Atlântica, a Lei Federal impõe, através de seu art. 17, o dever de compensar a intervenção por meio da destinação de área para a conservação ou da reposição florestal, observando as mesmas características ecológicas, a mesma bacia hidrográfica; sempre que possível, a mesma microbacia e o mesmo município, quando se tratar de loteamentos e edificações em áreas urbanas. O dever de compensar também está disposto no art. 32 da Lei Federal, específico para as atividades minerárias, trazendo a obrigatoriedade de adoção de medida compensatória que inclua a recuperação de área equivalente à do empreendimento, na mesma bacia hidrográfica, sempre que possível na mesma microbacia, e atendendo ao critério de mesmas características ecológicas da área suprimida (Brasil 2006b).

A competência para o estabelecimento da condicionante de compensação por intervenção em vegetação nativa do bioma Mata Atlântica, em Minas Gerais, é das SUPRAMs, da Superintendência de Projetos Prioritários (SUPPRI), das Unidades Regionais de Florestas e Biodiversidade (URFBio) do IEF, dos Núcleos de Apoio Regional (NARs) e de demais unidades administrativas do IEF ou Semad autorizadas a analisar requerimentos de supressão de vegetação nativa do bioma Mata Atlântica.

A emissão de parecer opinativo sobre os processos de compensação é de responsabilidade das Unidades Regionais do IEF, que devem observar as diretrizes e os procedimentos para a análise e o cumprimento dessa compensação, descritos nas normativas relacionadas.

Atualmente, a Portaria IEF nº 30/2015 é a norma que estabelece os procedimentos para a análise de processos da referida compensação, sendo também a normativa que instituiu a descentralização dessa análise às Unidades Regionais do IEF (IEF 2015b).

O detalhamento dos procedimentos administrativospara fixação, análise e deliberação da compensação pelo corte ou supressão de vegetação primária ou secundária em estágio médio ou avançado de regeneração no bioma Mata Atlântica no estado de Minas Gerais está descrito atualmente na Instrução de Serviço Conjunta Semad/IEF $n^{\circ}$ 02/2017 (Semad \& IEF 2017). É destacada a exigência de compensação em área equivalente ao dobro da área intervinda, conforme disposto no artigo $4^{\circ}, \S 4^{\circ}$, da Deliberação Normativa Copam $n^{\circ}$ 73/2004 (Copam 2004), e como disposto na Recomendação MP no 05/2013, expedida pelo Ministério Público de Minas Gerais.

As formas de cumprimento da compensação, a serem adotadas pelo empreendedor, devem considerar as opções fornecidas pelos art. 26 $e$ art. 27, do Decreto Federal $n^{\circ}$ 6.660/2008: constituição de Reserva Particular do Patrimônio Natural (RPPN), instituição de servidão ambiental, ou doação de área localizada em unidade de conservação de domínio público pendente de regularização fundiária. $\mathrm{E}$, na impossibilidade de atendimento aos requisitos ambientais para a destinação de área à compensação, será admitida, ainda, a reposição florestal/recuperação de área com espécies nativas. Ressalta-se que, para as atividades minerárias, existe regra específica a ser seguida, conforme inciso II, art. 32, da Lei Federal no 11.428/2006 (Brasil 2006b, Brasil 2008).

Após a emissão de parecer opinativo pelas Unidades Regionais do IEF, os processos passam por deliberação da CPB, das URCs, das Câmaras de Atividades Minerárias (CIMs), de Atividades Industriais (CIDs), de Atividades Agrossilvipastoris (CAPs) ou de Atividades de Infraestrutura de Energia, Transporte, Saneamento e Urbanização (CIFs), conforme Decreto Estadual no 46.953, de 23 de fevereiro de 2016, alterado pelo Decreto Estadual $n^{\circ} 47.565$, de 19 de dezembro de 2018 (Minas Gerais 2016).

A aprovação dessa compensação deve ser feita pela $\mathrm{CPB} / \mathrm{Copam}$, conforme inciso XIV do art. 13, quando se tratar de processo de intervenção ambiental em que a compensação for destinada à UC estadual de domínio público. No caso de processos de intervenção ambiental em que houver supressão de vegetação secundária em estágio médio ou avançado de regeneração e em áreas prioritárias para a conservação da biodiversidade de empreendimentos não passíveis de licenciamento ambiental ou passiveis de licenciamento ambiental simplificado, a compensação deve ser aprovada pelas URCs, conforme inciso VIII do artigo $9^{\circ}$. Nos casos de processo de licenciamento ambiental, considerando a natureza da atividade ou empreendimento de sua área de competência - a) de médio porte e grande potencial poluidor; b) de grande porte $e$ médio potencial poluidor; ou c) de grande porte e grande potencial poluidor -, a aprovação dessa compensação deve ser feita no âmbito da CIM, CID, CAP, ou CIF, conforme inciso VI do art. 14. 


\section{Compensação por Empreendimentos Minerários (Lei Estadual no 20.922/2013)}

Instituída inicialmente pela Lei Estadual $n^{\circ} 14.309 / 2002$, esta medida compensatória é uma exclusividade do estado de Minas Gerais, caracterizado pelo grande número de empreendimentos minerários localizados em sua área de abrangência e, hoje em dia, pelos maiores desastres ambientais do país, como o rompimento de barragens de rejeitos minerários.

Diante dos benefícios advindos das atividades minerárias, sabe-se que, assim como várias outras atividades econômicas desenvolvidas pelo homem, diversas são as alterações e os danos ambientais provocados. Saidelles et al. (2001) afirmam que, embora sejam utilizadas técnicas avançadas e modernas para amenizar a degradação produzida pelos empreendimentos minerários, muitos procedimentos necessários para a instalação dessas atividades não podem ser evitados, causando grandes modificações no meio biótico. Vasconcelos et al. (2014) sinalizam para os conflitos sociais relacionados à implantação $e$ operação da atividade minerária em virtude da sua interferência nas áreas vizinhas à área minerada. Não pode ser desconsiderada também a alteração significativa da paisagem, que, em alguns casos, jamais retornará ao estado anterior à extração do bem mineral.

Barreto (2001) já defendia que, dada a especificidade do setor mineral, sua relação com o meio ambiente é mais complexa do que a maioria dos setores econômicos, apresentando rigidez locacional, e que a forma de ocorrência e o tipo do bem mineral implicam o uso de determinadas tecnologias e aproveitamentos adequados a essas realidades. Soma-se a isso o fato de que o objeto da atividade mineral é a extração de um recurso natural não renovável e que, por isso mesmo, a reconstituição da área torna-se impossível.

Nesse sentido, faz-se extremamente importante o reconhecimento dos danos ambientais associados a esse tipo de atividade, assim como é necessário o controle desses impactos negativos, de forma a impedir que os prejuízos sejam impostos à sociedade.

Há pouco tempo, o estado de Minas Gerais foi severamente impactado pelo rompimento de duas barragens de disposição de rejeitos de minério de ferro. Uma delas, conhecida como barragem de Fundão, pertencente à mineradora Samarco S.A., rompeu, em 5 de novembro de 2015, no município de Mariana, ocasionando o mais grave desastre ambiental da história do Brasil e do mundo, com o extravasamento de, aproximadamente, 34 milhões de metros cúbicos de rejeitos de minério de ferro, a destruição completa do distrito de Bento Rodrigues e a morte de 19 pessoas. A lama atingiu o Rio Doce, percorrendo cerca de $660 \mathrm{~km}$ até chegar ao oceano Atlântico, no estado do Espírito Santo (Serra 2018).

Em 25 de janeiro de 2019, ocorreu o rompimento de Barragem da Mina do Córrego do Feijão, controlada pela Vale S.A, e localizada no município de Brumadinho. O extravasamento dos rejeitos atingiu o rio Paraopeba, além de ter ocasionado a morte de 272 pessoas. O rompimento causou o maior número de óbitos e desaparecidos entre os desastres tecnológicos da indústria de mineração de ferro já relatados mundialmente (CPI 2019).

Percebe-se, desse modo, a importância de existir um compromisso entre as políticas públicas, os órgãos ambientais e as empresas, para implantar medidas mitigadoras, de acordo com os preceitos do desenvolvimento sustentável, e de forma a estabelecer uma relação mais equilibrada entre a necessária intervenção humana $e$ a conservação ambiental (Vasconcelos et al. 2014).

A compensação por empreendimentos minerários estabeleceu, a todos os empreendimentos desse tipo, o dever da adoção de medida compensatória que inclua a regularização fundiária $e$ a implantação de unidade de conservação de proteção integral (art. 75 da Lei Estadual no 20.922/2013), ou a criação, implantação ou manutenção de unidades de conservação de proteção integral (art. 36 da Lei Estadual n 14.309/2002) (Minas Gerais 2013, Minas Gerais 2002).

O estabelecimento da condicionante de compensação por empreendimentos minerários deve ser feito no âmbito dos pedidos de autorização de supressão de vegetação nativa, e a emissão de Parecer Único opinativo sobre a aceitação ou não da proposta é de competência das Unidades Regionais do IEF.

Em análise do texto legal (art. $36, \S 1^{\circ}$ e $\S 2^{\circ}$ da Lei Estadual $n^{\circ}$ 14.309/2002), depreende-se que, para o cumprimento da compensação, o 
empreendedor deve apresentar proposta que inclua a criação, implantação ou manutenção de unidades de conservação de proteção integral. A área a ser destinada à compensação não deve ser inferior à área utilizada pelo empreendimento, para extração do bem mineral, construção de estradas, construções diversas, beneficiamento ou estocagem, embarque e outras finalidades, devendo ser utilizada como referência a Área Diretamente Afetada (ADA) da atividade licenciada. Além disso, essa área deve estar localizada na mesma bacia hidrográfica (bacia federal) e, preferencialmente, no município onde está instalado o empreendimento (Minas Gerais 2002).

Com a publicação da Lei Estadual $n^{\circ}$ 20.922/2013, revogou-se a Lei Estadual $n^{\circ} 14.309 / 2002$; entretanto, consta no art. 75 a manutenção da obrigatoriedade do cumprimento da compensação por empreendimentos minerários.

Algumas diferenças podem ser verificadas com relação aos critérios estabelecidos no art. 36 da Lei Estadual $n^{\circ} 14.309 / 2002$ e os novos critérios estabelecidos pela Lei Estadual $n^{\circ}$ 20.922/2013. Na Lei Estadual publicada em 2013, a área proposta para a compensação ambiental não deve ser inferior à área de vegetação nativa suprimida pelo empreendimento, para extração do bem mineral, construção de estradas, construções diversas, beneficiamento ou estocagem, embarque $e$ outras finalidades, de acordo com a autorização de supressão fornecida pelo órgão licenciador. Já a lei anterior previa a observância da área utilizada pelo empreendimento. De acordo com o art. 75, também não é necessária a observância do critério locacional associado à bacia hidrográfica ou ao município, o que era obrigatório pela Lei Estadual no 14.309/2002 (Minas Gerais 2002, Minas Gerais 2013).

Ainda que tenha havido a revogação da Lei Estadual n ${ }^{\circ} 14.309 / 2002$, as disposições do art. 36 foram abarcadas pelo $\S 2^{\circ}$ do art. 75 da Lei Estadual n ${ }^{\circ} 20.922 / 2013$, impondo-se a todo empreendimento minerário, em processo de regularização ambiental ou já regularizado, que não tenha cumprido, até a data da sua publicação (17 de outubro de 2013), a medida compensatória instituída pelo art. 36, a observância dos critérios estabelecidos no artigo citado (Minas Gerais 2002, Minas Gerais 2013).

Atualmente, os procedimentos para o cumprimento dessa medida compensatória estão descritos na Portaria IEF n ${ }^{\circ} 27$, de 07 de abril de 2017 (IEF 2017), conforme a seguir:

I - destinação, mediante doação ao Poder Público, de área localizada no interior de unidade de conservação de proteção integral pendente de regularização fundiária;

II - destinação, mediante doação ao Poder Público, de área considerada de relevante interesse ambiental para a criação de unidade de conservação de proteção integral pelo estado de Minas Gerais. Nesse caso, além da aquisição da área e consequente doação para o estado, o empreendedor deverá garantir a implantação de estrutura mínima necessária à gestão da unidade de conservação, a qual inclui a construção de portaria de acesso, sede administrativa e centro de visitantes, o cercamento total da UC e a elaboração do plano de manejo. As propostas de criação de UC serão analisadas tomando-se por base a política de prioridades estabelecidas pelo IEF, em conformidade com as diretrizes técnicas ditadas pela Diretoria de Unidades de Conservação (DIUC);

III - execução de medida compensatória que vise à implantação de unidade de conservação estadual de proteção integral, a qual inclui a elaboração do plano de manejo, a implantação de estruturas necessárias à sua gestão $e$ funcionamento, bem como a realização de estudos técnicos necessários à sua gestão;

IV - medida compensatória que vise à manutenção de unidade de conservação estadual de proteção integral.

No caso do cumprimento da compensação por meio dos incisos I e II, o empreendedor deverá adquirir área(s) visando à doação para o Poder Público, mediante registro da Escritura Pública de Doação perante o Cartório de Registro de Imóveis Competente, ficando gravado, à margem da matrícula, o número do processo de intervenção de que trata a referida compensação (IEF 2017).

Os Pareceres Únicos devem ser submetidos à análise e aprovação da $\mathrm{CPB} / \mathrm{Copam}$ (Minas Gerais 2016). 


\section{Regularização Ambiental e Adequação das Propriedades Rurais}

O ordenamento jurídico brasileiro estabelece limitações gerais que regem a propriedade florestal, as quais estão em consonância com as definições da Constituição Federal. Dentre essas restrições, está a obrigatoriedade da observância das áreas de uso restrito, das áreas de preservação permanente e das reservas legais (Antunes 2013).

Atualmente, a Lei Federal $\mathrm{n}^{\circ}$ 12.651, de 2012, popularmente conhecida como Novo Código Florestal, disciplina, dentre outros assuntos, as áreas de reserva legal. Essa lei trouxe a definição de reserva legal, adaptando-a à realidade atual $e$ à necessidade de compatibilização entre o desenvolvimento econômico e a proteção ambiental, conforme seu artigo $3^{\circ}$, inciso III: "área localizada no interior de uma propriedade ou posse rural, delimitada nos termos do art. 12, com a função de assegurar o uso econômico de modo sustentável dos recursos naturais do imóvel rural, auxiliar a conservação $e$ a reabilitação dos processos ecológicos $e$ promover a conservação da biodiversidade, bem como o abrigo e a proteção de fauna silvestre $e$ da flora nativa" (Brasil 2012).

A obrigação legal da instituição $e$ manutenção de área de reserva legal deve observar o disposto no art. 12 da supracitada Lei Federal, no que se refere aos percentuais a serem conservados. No estado de Minas Gerais, deve ser conservado $20 \%$ (vinte por cento) da área total do imóvel rural, tendo em vista que o estado possui os biomas Mata Atlântica, Cerrado e Caatinga, e está fora da área da Amazônia Legal. De acordo com o estabelecido no $\S 1^{\circ}$ do art. 17 da Lei, é admitida a exploração da reserva legal por meio do manejo sustentável, desde que aprovado por órgão integrante do Sistema Nacional do Meio Ambiente (Sisnama) (Brasil 2012).

Uma inovação da Lei Federal de 2012 foi a criação do Cadastro Ambiental Rural (CAR), sistema por meio do qual deve se dar o registro da área de reserva legal perante o órgão ambiental. A inexigibilidade de averbação de reserva legal, no entanto, não deve ser confundida com a dispensa dessa obrigação, que possui natureza real e é transmitida ao sucessor no caso de transferência de domínio ou posse do imóvel rural.

\section{Compensação de Reserva Legal (Lei Federal $n^{\circ}$ 12.651/2012)}

O Código Florestal de 1934 trouxe o que pode ser chamado de instituto precursor da reserva legal, tendo em vista que era estabelecido, aos proprietários de áreas cobertas por vegetação, o limite da derrubada de até três quartos da área, devendo a quarta parte, portanto, ser preservada (Milaré 2014).

Três décadas após, com o advento da Lei Federal $n^{\circ} 4.771$, em 1965, veio o reconhecimento da importância das florestas existentes no território nacional, conforme consta no artigo $1^{\circ}$ da referida Lei, que afirma que as florestas e demais formas de vegetação existentes no território nacional são bens de interesse comum a todos os habitantes do país, onde os direitos de propriedade devem ser exercidos com as limitações estabelecidas na legislação (Brasil 1965).

Milaré (2014) afirma que o Código Florestal de 1965 estabeleceu as áreas de proteção permanente (APPs) e também determinou a instituição, em todo e qualquer imóvel rural, de uma reserva em parte do solo, impondo limites ou restrições ao exercício do direito de propriedade. A princípio, o texto legal trazia uma preocupação predominantemente econômica, focada na manutenção de fonte de abastecimento de madeira, conceito bem diverso do adotado, após sucessivas modificações pelas quais passou o texto legal, principalmente após a Constituição Federal de 1988, quando ganhou concepção nitidamente ecológica.

Com o passar dos anos e a mudança da realidade econômica brasileira, os limites e restrições impostos pela Lei Federal n ${ }^{\circ}$ 4.771/1965 passaram a incomodar os proprietários rurais (Figueiredo \& Leuzinger 2001). A pressão por mudanças da legislação aumentou, trazendo como consequência a edição da Lei Federal n 12.651 , de 25 de maio de 2012.

Conforme descrito na Lei Federal $\mathrm{n}^{\circ} 12.651 / 2012$, os proprietários ou possuidores de imóveis rurais que, em 22 de julho de 2008, detinham área de reserva legal em extensão inferior ao percentual mínimo exigido pela normativa federal, deveriam buscar algum dos mecanismos para a regularização dos seus imóveis. Tais mecanismos estão descritos no art. 66 da referida Lei e podem ser adotados de forma isolada ou conjuntamente: I - recompor a reserva legal; 
II - permitir a regeneração natural da vegetação na área de reserva legal; III - compensar a reserva legal (Brasil 2012).

Com o advento da Lei Federal $\mathrm{n}^{\circ} 12.651 / 2012$, foi estabelecida a obrigatoriedade de a compensação da reserva legal deficitária ser precedida pela inscrição da propriedade no CAR, podendo ser adotadas as seguintes alternativas descritas no $\S 5^{\circ}$ do art. 66: I - aquisição de Cota de Reserva Ambiental (CRA); II - arrendamento de área sob regime de servidão ambiental ou reserva legal; III - doação ao Poder Público de área localizada no interior de unidade de conservação de domínio público pendente de regularização fundiária; IV - cadastramento de outra área equivalente e excedente à reserva legal, em imóvel de mesma titularidade ou adquirida em imóvel de terceiro, com vegetação nativa estabelecida, em regeneração ou recomposição, desde que localizada no mesmo bioma (Brasil 2012).

As áreas destinadas à compensação da reserva legal devem, obrigatoriamente, ser equivalentes em extensão à área de reserva legal a ser compensada, estar localizadas no mesmo bioma da área a ser compensada e, se localizadas fora do estado, devem estar localizadas em áreas identificadas como prioritárias pela União ou pelos estados, de acordo com $\S 6^{\circ}$ do art. 66 da Lei Federal no 12.651/2012 (Brasil 2012).

Conforme dados obtidos com a Gerência de Cadastro Ambiental Rural (GCAR) do IEF, até julho de 2019 Minas Gerais possuía, aproximadamente, 760 mil imóveis rurais inseridos no Cadastro Ambiental Rural, com uma área de mais de 42 milhões de hectares. A partir desse Cadastro, também pôde ser identificado um grande passivo ambiental relacionado à necessidade de regularização de áreas de preservação permanente e reservas legais no território mineiro (resultados não publicados).

Para a compensação de reserva legal em Minas Gerais, devem ser observados os requisitos dispostos no inciso III, $\S 5^{\circ}$, do art. 38 da Lei Estadual $n^{\circ}$ 20.922/2013: possuir equivalência em extensão à área de reserva legal a ser compensada; localização no mesmo bioma da área de reserva legal a ser compensada; estar previamente identificada como prioritária pela União ou pelo estado de destino, se a propriedade ou posse rural estiver localizada no estado de Minas Gerais e o proprietário ou o possuidor rural desejar fazer a compensação em outro estado; estar previamente identificada como prioritária pela União ou pelo estado de Minas Gerais, se a propriedade ou posse rural estiver localizada fora de Minas Gerais e o proprietário ou o possuidor rural desejar fazer a compensação no estado, mediante autorização do órgão ambiental mineiro (Minas Gerais 2013).

Em uma demonstração da importância dada pelo legislador ao equacionamento da questão fundiária de UC no estado, a lei estadual mencionou que a identificação de áreas prioritárias objetivará favorecer, entre outros aspectos, a regularização fundiária de UC de domínio público.

A análise das propostas de compensação de reserva legal em áreas de UC de domínio público no estado de Minas Gerais deve observar a Deliberação Normativa Copam n 200, de 13 de agosto de 2014 (Copam 2014), e a Resolução Conjunta Semad/IEF $\mathrm{n}^{\circ} 2.225$, de 26 de novembro de 2014 (Semad \& IEF 2014).

\section{Panorama das Unidades de Conservação Estaduais em Minas Gerais}

Drummond et al. (2005) ressaltam que Minas Gerais possui uma infinidade de paisagens com ambientes únicos e uma cobertura vegetal nativa rica e diversa, agrupada em três biomas: a Mata Atlântica, o Cerrado e a Caatinga.

Seguindo um modelo de ocupação característico do Brasil, entretanto, essa diversidade encontra-se fortemente ameaçada, devido a processos históricos de uma ocupação territorial desordenada e pouco preocupada com a preservação e a conservação ambiental (Ayres et al. 2005, Drummond et al. 2005), o que levou a uma demanda cada vez maior para o estabelecimento de áreas protegidas.

As UCs estaduais de Minas Gerais são geridas pelo IEF, autarquia vinculada à Semad $e$ criada pela Lei Estadual no 2.606, de 5 de janeiro de 1962 (Minas Gerais 1962).

Atualmente, o estado possui 94 UCs estaduais distribuídas nas categorias de proteção integral e de uso sustentável do SNUC, com uma área total de 2.299.963,73 hectares, ou representando, aproximadamente, $3,92 \%$ do território mineiro (IEF 2019). Foram excluídas as RPPNs, tendo em vista que não se trata de UCs geridas pelo estado, mas por particulares. 


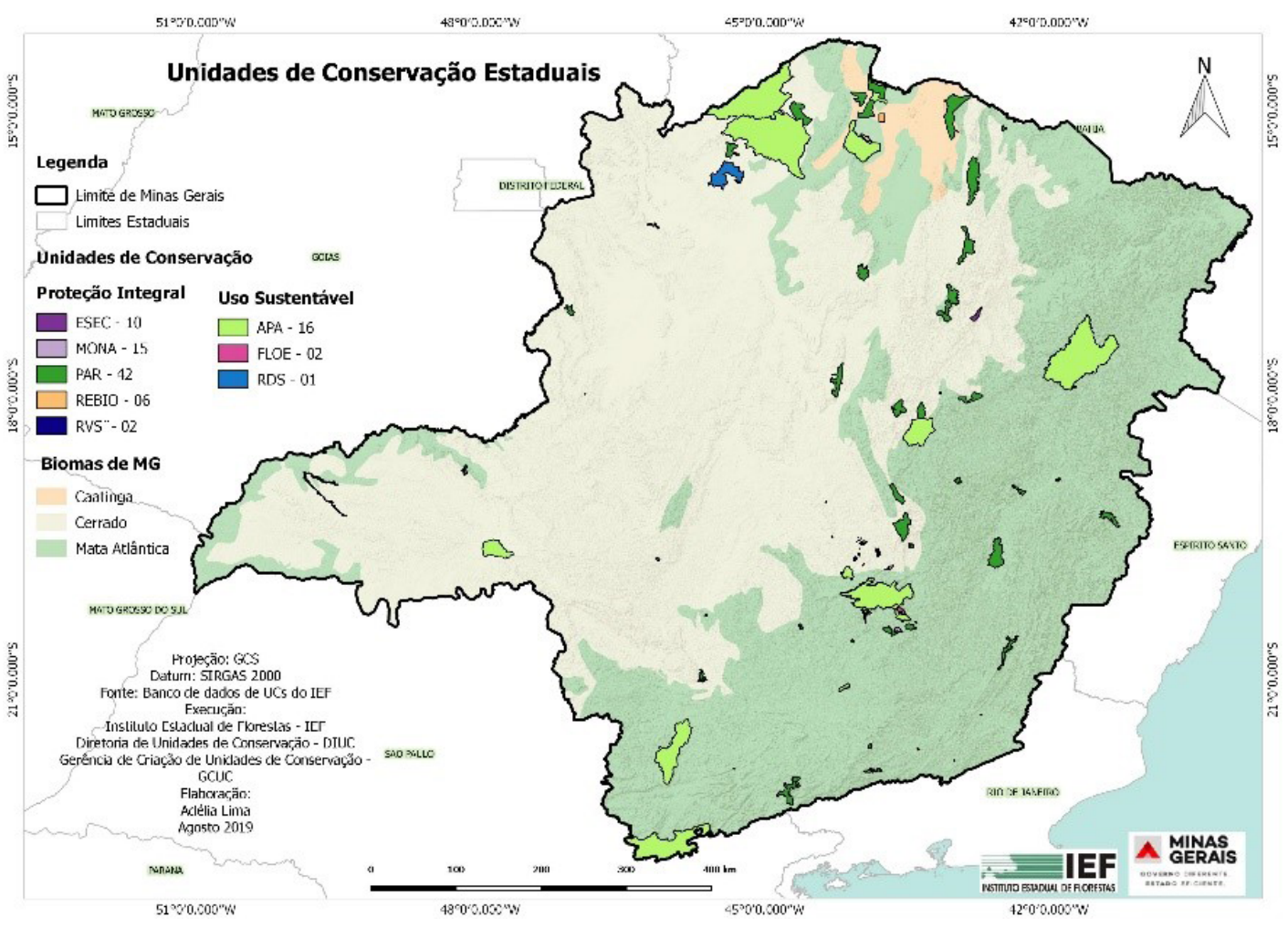

Figura 1 - Distribuição das UCs estaduais em Minas Gerais (IEF 2019).

Com relação ao Grupo de Proteção Integral, existem atualmente 73 UCs geridas pelo estado com uma área total de 533.669,63 hectares, distribuídas nas seguintes categorias de manejo: estação ecológica, monumento natural, parque estadual, refúgio da vida silvestre e reserva biológica (Tabela 2).

Tabela 2 - UCs estaduais de proteção integral de Minas Gerais.

\begin{tabular}{|c|c|c|c|c|}
\hline CATEGORIA & $\begin{array}{c}\text { NÚMERO } \\
\text { DE UC }\end{array}$ & $\begin{array}{c}\text { \% DA CATEGORIA/ } \\
\text { TOTAL DO GRUPO }\end{array}$ & $\begin{array}{c}\text { ÁREA (EM } \\
\text { HECTARES) }\end{array}$ & $\begin{array}{c}\text { \% DE ÁREA DA CATEGORIA/ } \\
\text { TOTAL DO GRUPO }\end{array}$ \\
\hline Estação ecológica & 10 & $13,70 \%$ & $10.277,48$ & $1,92 \%$ \\
\hline Monumento natural & 15 & $20,55 \%$ & $11.684,59$ & $2,19 \%$ \\
\hline Parque estadual & 40 & $54,79 \%$ & $475.898,58$ & $89,18 \%$ \\
\hline Refúgio de vida silvestre & 06 & $8,22 \%$ & $25.610,03$ & $4,80 \%$ \\
\hline Reserva biológica & 02 & $2,74 \%$ & $10.198,95$ & $1,91 \%$ \\
\hline Total & $\mathbf{7 3}$ & $\mathbf{1 0 0 \%}$ & $\mathbf{5 3 3 . 6 6 9 , 6 3}$ & $\mathbf{1 0 0 \%}$ \\
\hline
\end{tabular}

Com relação ao Grupo de Uso Sustentável, existem 19 UCs geridas pelo estado, com uma área total de 1.766.294,10 hectares, distribuídas nas seguintes categorias de manejo: área de proteção ambiental, floresta estadual e reserva de desenvolvimento sustentável (Tabela 3). 
Tabela 3 - UCs estaduais de uso sustentável de Minas Gerais.

\begin{tabular}{|c|c|c|c|c|}
\hline CATEGORIA & $\begin{array}{c}\text { NÚMERO } \\
\text { DE UC }\end{array}$ & $\begin{array}{c}\text { \% DA CATEGORIA/ } \\
\text { TOTAL DO GRUPO }\end{array}$ & $\begin{array}{c}\text { ÁREA (EM } \\
\text { HECTARES) }\end{array}$ & $\begin{array}{c}\text { \% DE ÁREA DA } \\
\text { CATEGORIA/ TOTAL } \\
\text { DO GRUPO }\end{array}$ \\
\hline $\begin{array}{c}\text { Área de proteção } \\
\text { ambiental }\end{array}$ & 16 & $84,21 \%$ & $1.700 .779,91$ & $96,29 \%$ \\
\hline Floresta estadual & 02 & $10,53 \%$ & $4.538,87$ & $0,26 \%$ \\
\hline $\begin{array}{c}\text { Reserva de } \\
\text { desenvolvimento } \\
\text { sustentável }\end{array}$ & 01 & $5,26 \%$ & $60.975,32$ & $3,45 \%$ \\
\hline Total & $\mathbf{1 9}$ & $\mathbf{1 0 0 \%}$ & $\mathbf{1 . 7 6 6 . 2 9 4 , 1 0}$ & $\mathbf{1 0 0 \%}$ \\
\hline
\end{tabular}

Do total de UCs geridas pelo estado, 55 são as que se enquadram em categorias que demandam, obrigatoriamente, ações de regularização fundiária, uma vez que são áreas sob domínio público e devem ser desapropriadas pelo poder público estadual: parques estaduais, estações ecológicas, reservas biológicas, florestas estaduais e reserva de desenvolvimento sustentável.

O "Diagnóstico e Plano de Trabalho para Criação, Implantação e Gestão das Unidades de Conservação Estaduais de Minas Gerais", elaborado por IEF \& Semad em 2014, demonstra que apenas $32,96 \%$ da área total das UCs de domínio público encontrava-se regularizada àquela época (resultados não publicados).

A busca por alternativas viáveis para a implantação de UCs e a resolução da sua situação fundiária torna-se fundamental para garantir os objetivos de conservação dessas áreas protegidas, a exemplo da utilização de mecanismos de compensação ambiental que possuem interface com a regularização fundiária. Caminhando neste sentido, o estado de Minas Gerais vem buscando viabilizar a execução desses mecanismos de compensação ambiental, por meio do estabelecimento de procedimentos para a formalização de processos e análise técnica das propostas apresentadas.

\section{Análise e Discussão}

Um dos principais entraves à implementação das áreas protegidas é a existência de conflitos difusos pelo uso da terra e dos recursos naturais. No entanto, observa-se que somente a atuação do Poder Público não é capaz de equacionar a situação fundiária das áreas protegidas e, assim, as compensações ambientais aparecem como uma alternativa relevante.

Os quatro tipos de compensações, objetos deste estudo, podem contribuir para a regularização fundiária de UCs estaduais de domínio público e, consequentemente, para a efetividade de gestão dessas áreas protegidas.

A compensação ambiental por significativo impacto ambiental (Lei Federal $n^{\circ}$ 9.985/2000) pode representar grande aporte de recursos destinados à implantação de UCs, incluindo ações de regularização fundiária. No entanto, observase uma tendência à utilização desses recursos em atividades de custeio das UCs, consumindo a maior parte dos recursos contabilizados.

Importante destacar, ainda, que não há garantias acerca da receita que será aportada aos cofres públicos por meio da compensação ambiental. Trata-se de recursos incertos e também finitos, oriundos de degradação ambiental, não sendo desejável que a compensação ambiental seja vislumbrada pelos órgãos gestores de UCs como uma fonte de arrecadação da qual depende a sobrevivência dessas áreas protegidas.

Outra questão a ser destacada é que, com exceção dos recursos destinados às UCs diretamente afetadas, a receita obtida por meio do cumprimento de compensação ambiental deve ser destinada às unidades de conservação de 
proteção integral e, desta forma, o investimento em UCs de uso sustentável deve ser abarcado por recursos oriundos de outras fontes, quando estas UCs não tiverem sido contempladas com recursos de compensação ambiental.

Ainda, a complexidade envolvida nas ações de desapropriação e regularização fundiária, que demandam o envolvimento de diversos setores $e$ instituições, tornam esses processos por vezes morosos, dificultando ou impedindo a utilização dos recursos oriundos dessa compensação com a celeridade esperada.

Com relação às compensações ambientais cujo cumprimento se dá com a destinação de áreas à conservação, a despeito do ganho ambiental e social envolvido no que se refere à regularização fundiária de UC, aponta-se para a sobreposição de compensação em UC já instituída, em detrimento do ganho de novas áreas de conservação por meio da instituição de RPPN, servidão ambiental ou reserva legal.

Em análise específica da compensação de Mata Atlântica, verifica-se que os critérios estabelecidos pela legislação federal podem tornar o desafio de encontrar áreas para o estabelecimento dessa compensação mais complicado, quando a procura se restringe a áreas localizadas em UCs de domínio público. Por outro lado, a opção pela compensação através da instituição de RPPN ou servidão ambiental possibilita um aumento de áreas com vegetação nativa conservadas.

Já com relação à compensação de reserva legal em UC, destaca-se que as reservas legais $e$ as UCs configuram-se como instrumentos legais de conservação com características diversas. A reserva legal possui objetivos de conservação que permitem o uso sustentável/manejo dos seus recursos, além de estar localizada de forma dispersa nos imóveis rurais. As UCs não possuem localização tão difusa quanto a das reservas legais $e$, no caso das categorias de UCs de proteção integral (parques nacionais, reservas biológicas e estações ecológicas), é obrigatório o domínio público das áreas, sendo admitido apenas o uso indireto de recursos naturais. Os monumentos naturais e refúgios de vida silvestre podem ser constituídos por áreas particulares, desde que seja possível compatibilizar os objetivos da unidade com a utilização da terra e dos recursos naturais do local pelos proprietários.

\section{Considerações Finais}

Infere-se que a compensação por empreendimentos minerários é a que se apresenta como a mais promissora e propícia para a regularização fundiária de unidades de conservação estaduais de domínio público em Minas Gerais. São diversos os fatores que levaram a essa conclusão: a) trata-se do estado com o maior número de empreendimentos minerários do país; b) é uma compensação voltada especificamente à implantação e regularização fundiária de unidades de conservação; c) não envolve o recolhimento de recursos financeiros para a conta do estado, havendo a aplicação direta de recursos pelo empreendedor na aquisição das áreas; d) não apresenta conflitos com outros institutos de preservação/conservação ambiental.

Somada à sua contribuição para a regularização fundiária de UCs de proteção integral, verifica-se que esse tipo de compensação pode apresentar um papel relevante para a ampliação das áreas protegidas no estado de Minas Gerais, uma vez que a criação e a ampliação de UCs de proteção integral também se configuram como alternativas para o cumprimento desse tipo de compensação.

\section{Referências Bibliográficas}

Antunes P de B. 2013. Manual de direito ambiental. 5 ed. Atlas. 416p.

Ayres JM et al. 2005. Os corredores ecológicos das florestas tropicais do Brasil. Sociedade Civil do Mamirauá. 256p.

Barreto ML. 2001. Mineração e desenvolvimento sustentável: desafios para o Brasil. CETEM/MCT. 225p.

Bechara E. 2007. Uma contribuição ao aprimoramento do instituto da compensação ambiental prevista na Lei $n^{\circ}$ 9.985/2000. 353p.

Bechara E. 2011. A compensação ambiental prevista no artigo 36 da Lei do SNUC. Apresentação: Congresso do Ministério Público de Meio Ambiente da Região Sudeste. 23p.

Brandão HB, Mendes L, Mexias TM. 2010. Desafios para o georreferenciamento de imóveis rurais localizados em unidades de conservação estaduais do Rio de Janeiro. P. 36-56. In: Albuquerque DP, Brandão H Bortolo, Campos Honora AC de, Castro Mendes CA de (orgs.). Regularização fundiária em unidades de conservação: as experiências dos estados do Rio de Janeiro, São Paulo e Minas Gerais/Instituto Estadual 
do Ambiente, Instituto Estadual de Florestas, Fundação para Conservação e a Produção Florestal do Estado de São Paulo. 140p.

Brasil. Lei $\mathrm{n}^{\circ}$ 4.771, de 15 de setembro de 1965 . Diário Oficial da União. < http://www.planalto.gov.br/ ccivil_03/leis/14771.htm > . Acesso em: 27/08/2019.

Brasil. Lei no 6.938, de 31 de agosto de 1981. Diário Oficial da União. <http://www.planalto.gov.br/ccivil_03/ leis/16938compilada.htm > . Acesso em: 27/08/2019.

Brasil. Constituição da República Federativa do Brasil: promulgada em 5 de outubro de 1988. Contêm as emendas constitucionais posteriores. Diário Oficial da União. http://www.planalto.gov.br/ccivil_03/ constituicao/constituicaocompilado.htm. Acesso em: 27/08/2019.

Brasil. Lei no 9.985, de 18 de julho de 2000. Diário Oficial da União. <http://www.planalto.gov.br/ccivil 03/ leis/19985.htm > . Acesso em: 27/08/2019.

Brasil. Decreto $\mathrm{n}^{\circ}$ 4.339, de 22 de agosto de 2002. Diário Oficial da União. <http://www.planalto.gov. br/ccivil_03/decreto/2002/D4339.htm>. Acesso em: 27/08/2019.

Brasil. Decreto $\mathrm{n}^{\circ}$ 4.340, de 22 de agosto de 2002. Diário Oficial da União. <http://www.planalto.gov. br/ccivil 03/decreto/2002/D4340.htm>. Acesso em: 27/08/2019.

Brasil. Decreto 5.758, de 13 de abril de 2006. Diário Oficial da União. <http://www.planalto.gov.br/ ccivil_03/_Ato2004-2006/2006/Decreto/D5758.htm>. Acesso em: 27/08/2019.

Brasil. Lei $\mathrm{n}^{\circ}$ 11.428, de 22 de dezembro de 2006. Diário Oficial da União. <http://www.planalto.gov.br/ ccivil_03/_Ato2004-2006/2006/Lei/L11428.htm > . Acesso em: 27/08/2019.

Brasil. Decreto $n^{\circ}$ 6.660, de 21 de novembro de 2008. Diário Oficial da União. <http://www.planalto.gov.br/ ccivil_03/_ato2007-2010/2008/decreto/d6660.htm > . Acesso em: 27/08/2019.

Brasil. Decreto $\mathrm{n}^{\circ}$ 6.848, de 14 de maio de 2009. Diário Oficial da União. <http://www.planalto.gov.br/ ccivil_03/_Ato2007-2010/2009/Decreto/D6848.htm > . Acesso em: 27/08/2019.

Brasil. Lei $\mathrm{n}^{\circ}$ 12.651, de 25 de maio de 2012. Diário Oficial da União. <http://www.planalto.gov. br/ccivil_03/_ato2011-2014/2012/lei/112651.htm > . Acesso em: 27/08/2019.

Butchart SHM et al. 2012. Protecting Important Sites for Biodiversity Contributes to Meeting Global Conservation Targets. 8p. <www.plosone.org $>$. Acesso em: 28/03/2014.
Comissão Parlamentar de Inquérito da Câmara dos Deputados. 2019. Rompimento da Barragem de Brumadinho: Relatório Final da CPI. Presidente: Deputado Júlio Delgado e Relator: Deputado Rogério Correia. Brasília - DF. <https://www.camara.leg.br/ internet/comissoes/cpi/cpibruma/RelatorioFinal.pdf $>$. Acesso em: 17/02/2020.

Copam (Conselho Estadual de Política Ambiental). Deliberação Normativa $n^{\circ} 73$, de 08 de setembro de 2004. Diário Oficial de Minas Gerais. <http://www. siam.mg.gpv.br/sla/dowload.pdf?idNorma $=164>$. Acesso em: 22/10/2013.

Copam (Conselho Estadual de Política Ambiental). Deliberação Normativa $\mathrm{n}^{\circ} 200$, de 13 de agosto de 2014. Diário Oficial de Minas Gerais. <http://www. siam.mg.gpv.br/sla/dowload.pdf?idNorma $=5203>$. Acesso em: 27/08/2019.

Costa SS. 2008. Compensação ambiental: uma opção para implementação do Sistema Nacional de Unidades de Conservação da Natureza (SNUC). Anais do IV Encontro Nacional da ANPPAS. Brasília, DF. 22p.

Drummond GM et al. 2005. Biodiversidade em Minas Gerais: um atlas para sua conservação. 2 ed. Fundação Biodiversitas. 222p.

Figueiredo GJP, Leuzinger MD. 2001. Desapropriações ambientais na Lei n ${ }^{\circ}$ 9.985/00. p. 465 - 489. In: Benjamin $\mathrm{AH}$ (org.). Direito ambiental das áreas protegidas: o regime jurídico das unidades de conservação. Forense Universitária. 547p.

Fundação SOS Mata Atlântica \& Instituto Nacional de Pesquisas Espaciais. 2009. Atlas dos remanescentes florestais da Mata Atlântica: Período 2005-2008. < http:// www.mapas.sosma.org > . Acesso em 20/07/2015.

Fundação SOS Mata Atlântica \& Instituto Nacional de Pesquisas Espaciais. 2013. Atlas dos remanescentes florestais da Mata Atlântica: Período 2011-12. < http:// www.mapas.sosma.org > . Acesso em: 17/02/2020.

Fundação SOS Mata Atlântica \& Instituto Nacional de Pesquisas Espaciais. 2014. Atlas dos remanescentes florestais da Mata Atlântica: Período 2012-13. < http:// www.mapas.sosma.org >. Acesso em: 17/02/2020.

Fundação SOS Mata Atlântica \& Instituto Nacional de Pesquisas Espaciais. 2015. Atlas dos remanescentes florestais da Mata Atlântica: Período 2013-14. <http:// www.mapas.sosma.org >. Acesso em: 17/02/2020.

Fundação SOS Mata Atlântica \& Instituto Nacional de Pesquisas Espaciais. 2016. Atlas dos remanescentes florestais da Mata Atlântica: Período 2014-15. <http:// www.mapas.sosma.org > . Acesso em: 17/02/2020.

Fundação SOS Mata Atlântica \& Instituto Nacional de Pesquisas Espaciais. 2017. Atlas dos remanescentes florestais da Mata Atlântica: Período 2015-16. < <http:// www.mapas.sosma.org >. Acesso em: 17/02/2020. 
Fundação SOS Mata Atlântica \& Instituto Nacional de Pesquisas Espaciais. 2018. Atlas dos remanescentes florestais da Mata Atlântica: Período 2016-17. < http:// www.mapas.sosma.org >. Acesso em: 17/02/2020.

Fundação SOS Mata Atlântica \& Instituto Nacional de Pesquisas Espaciais. 2019. Atlas dos remanescentes florestais da Mata Atlântica: Período 2017-18. < http:// www.mapas.sosma.org >. Acesso em: 17/02/2020.

Guatura IS, Corrêa F, Costa JP de O, Azevedo PUE de. 1996. A questão fundiária: roteiro para a solução dos problemas fundiários nas áreas protegidas da Mata Atlântica. 24p. <http://www.rbma.org.br/rbma/pdf/ Caderno_01.pdf $>$. Acesso em: 23/01/2014.

IEF (Instituto Estadual de Florestas). Portaria IEF n ${ }^{\circ} 55$, de 23 de abril de 2012. Diário Oficial de Minas Gerais. <http:/www.siam.mg.gov.br/sla/download. pdf?idNorma $=21117>$. Acesso em: 22/10/2013.

IEF(InstitutoEstadualdeFlorestas).2015a.Apresentação sobre Compensação Ambiental e Florestal. Item 10 da $164^{a}$ Reunião Ordinária do Plenário do Conselho Estadual de Política Ambiental - Copam. <http:// www.meioambiente.mg.gov.br/copam/reuniao-deplenario>. Acesso em: 15/02/2020.

IEF (Instituto Estadual de Florestas). Portaria IEF n ${ }^{\circ}$ 30, de 03 de fevereiro de 2015. Diário Oficial de Minas Gerais. <http:/www.siam.mg.gov.br/sla/download. pdf?idNorma $=37255>$. Acesso em: 27/08/2019.

IEF (Instituto Estadual de Florestas). Portaria IEF $\mathrm{n}^{\circ} 27$ de 07 de abril de 2017. Diário Oficial de Minas Gerais. <http:/www.siam.mg.gov.br/sla/download. pdf?idNorma $=44102>$. Acesso em: 27/08/2019.

IEF (Instituto Estadual de Florestas). 2018. Plano Operativo Anual - Exercício 2018. 30p.

IEF (Instituto Estadual de Florestas), 2019. Mapa de Distribuição das UC Estaduais em Minas Gerais. Belo Horizonte. <http://www.ief.mg.gov.br/images/ stories/2019/UCs/MAPA-UC.jpg > Acesso em: 27/08/2019.

Kury KA. 2009. Regularização fundiária em unidade de conservação: o caso do Parque Estadual do Desengano/RJ. Boletim do observatório ambiental Alberto Ribeiro Lamego. 16p. <http://www. essentiaeditora.iff.edu.br/index.php/boletim/article/ view/2177-4560.20090014>. Acesso em: 22/10/2013.

Leuzinger MD. 2013. Uso público em unidades de conservação. 19p. <https://pt.scribd.com/ document/234133209/Uso-Publico-Em-Unidades-deConservacao > . Acesso em: 27/08/2019.

Milaré E. 2014. Direito do ambiente. 9 ed. Revista dos Tribunais. 1680p.
Minas Gerais. Lei no 2.606, de 05 de janeiro de 1962. Diário Oficial de Minas Gerais. <https:/almg.gov.br/ legislacao/legilacao_mineir/lei.html?tipo=LEI\&numero $=2606 \&$ ano $=1962>$. Acesso em: 22/10/2013.

Minas Gerais. Lei n ${ }^{\circ}$ 14.309, de 19 de junho de 2002. Diário Oficial de Minas Gerais. <https:/almg.gov.br/ legislacao/legilacao_mineir/lei.html?tipo=LEI\&numero $=14309 \&$ ano $=200 \overline{2}>$. Acesso em: 22/10/2013.

Minas Gerais. Decreto n ${ }^{\circ} 45.175$, de 17 de setembro de 2009. Diário Oficial de Minas Gerais. < https://almg.gov. br/legislacao/legilacao_mineir/lei.html?tipo=DEC\&nu mero $=45175 \&$ ano $=2009>$. Acesso em: 22/10/2013.

Minas Gerais. Decreto $n^{\circ} 45.629$, de 06 de julho de 2011. Diário Oficial de Minas Gerais. < https://almg.gov. br/legislacao/legilacao_mineir/lei.html?tipo =DEC\&nu mero $=45629$ \&ano $=2011>$. Acesso em: 22/10/2013.

Minas Gerais. Lei n² 20.922, de 16 de outubro de 2013. Diário Oficial de Minas Gerais. < https://almg.gov.br/ legislacao/legilacao_mineir/lei.html?tipo=LEI\&numero $=20922 \&$ ano $=2013>$. Acesso em: 22/10/2013.

Minas Gerais. Decreto no 46.953, de 23 de fevereiro 2016. Diário Oficial de Minas Gerais. < https://almg.gov. br/legislacao/legilacao_mineir/lei.html?tipo=DEC\&nu mero $=46953 \&$ ano $=2016>$. Acesso em: 27/08/2019.

Nolte C, Agrawal A, Barreto P. 2013. Setting priorities to avoid deforestation in Amazon protected areas: área we choosing the right indicators? IOP Publishing. $8 \mathrm{p}$. <http://iopscience.iop.org/1748-9326/8/1/015039/ article $>$. Acesso em: 22/10/2013.

Oliveira LJD. 2010. Regularização fundiária de unidades de conservação. Boletim Científico: Escola Superior do Ministério Público da União. 37p. <http:/boletimcientifico.escola.mpu.mp.br/boletins/ boletim-cientifico-n.-32-33-janeiro-dezembro2010/regularizacao-fundiaria-de-unidades-deconservacao $>$. Acesso em: 22/10/2013.

Pádua JA. 2004. A ocupação do território brasileiro e a conservação dos recursos naturais. 12p. In: Milano M, Takahashi L \& Nunes M (orgs.). Atualidades e Tendências. Fundação O Boticário, Curitiba, 2004.

Pimm SL et al. 2001. Can we defy nature's end? 2p. <www.sciencemag.org > . Acesso em: 28/03/2014.

Pinto CEF. 2012. Compensação ambiental e empreendimentos minerários. P. 28-32. In: MPMG Jurídico - Revista do Ministério Público do Estado de Minas Gerais. Edição Especial Mineração. 74p.

Prates AP \& Sousa N. 2014. Panorama geral das áreas protegidas no Brasil: desafios para o cumprimento da meta 11 de Aichi, p. 82-118. In: Bensusan N. \& Prates AP (eds.). 2014. A diversidade cabe na unidade? Áreas protegidas do Brasil. Editora Mil Folhas IEB. 736p. 
Rocha LGM da, Drummond JA, Ganem RS. Parques nacionais brasileiros: problemas fundiários $e$ alternativas para a sua resolução. Revista de Sociologia e Política. 18(36): 205-226, 2010. <http://www. scielo.br/scielo.php?script $=$ sci_arttext $\&$ pid $=$ S0104 44782010000200013 >. Acesso em: 14/01/2014.

Saidelles FLF, König FG, Schumacher MV. 2001. A atividade mineradora, seus impactos e aspectos de sua recuperação - uma revisão de literatura. $1^{\circ}$ Simpósio Brasileiro de Pós-Graduação em Engenharia Florestal. $13 p$.

Semad (Secretaria de Estado de Meio Ambiente e Desenvolvimento Sustentável de Minas Gerais) \& IEF (Instituto Estadual de Florestas). 2014. Resolução Conjunta Semad/IEF no 2.225. <http://www.siam. mg.gpv.br/sla/dowload.pdf?idNorma $=35735>$. Acesso em: 27/08/2019.

Semad (Secretaria de Estado de Meio Ambiente e Desenvolvimento Sustentável de Minas Gerais) \& IEF (Instituto Estadual de Florestas). 2017. Instrução de Serviço Conjunta Semad/IEF no 02. http://www. meioambiente.mg.gov.br/images/stories/2017/ASNOP/ Instru\%C3\%A7\%C3\%A3o_de_Servi\%C3\%A7o_ Sisema_n\%C2\%BA_02-2017_2017.04.07-novo.pdf. Acesso èm: 27/08/2019.
Serra C. 2018. Tragédia em Mariana: A história do maior desastre ambiental do Brasil. Editora Record. 462p. <https://books.google.com.br/books/about/ Trag\%C3\%A9dia_em_Mariana.html?id=mQ10Dw AAQBAJ\&printsec $=$ frontcover\&source $=\mathrm{kp} \_$read button\&redir_esc $=y \# v=$ onepage \& $q=34 \% 2 \overline{0}$ milh\%C3\%B5es\&f=false $>$. Acesso em: 27/08/2019.

Stolton S \& Dudley N. 2010. Arguments for protected areas: multiple benefits for conservation and use. EarthScan. 273p.

Szabo AV, César BA, Santos LELSS, Santiago RV (elaboração). 2011. Programa consolidação territorial de unidades de conservação. Secretaria de Meio Ambiente da Bahia - SEMA e Instituto de Meio Ambiente e Recursos Hídricos. 24p.

Vasconcelos SCS, Vasconcelos CIS, Moraes Neto JM. Impactos ambientais decorrentes de mineração no entorno de zonas urbanas. Âmbito Jurídico, 17(121), 2014. <http://www.ambito-juridico.com.br/site/index.php/?n_ link=revista_artigos_leitura\&artigo_id $=14271 \&$ revista_ caderno $=5>$. Acesso em: 05/02/2015.

WWF Brasil. 2008. Unidades de conservação: conservando a vida, os bens e os serviços ambientais. 23p. $<$ http://www.mma.gov.br/estruturas/pda/_arquivos/prj_ mc_061_pub_car_001_uc.pdf>. Acesso em: 22/10/2013.

Biodiversidade Brasileira - BioBrasil.

Edição temática: Diálogos entre a Academia e a Gestão de Áreas Protegidas:

Programa de Pós-Graduação Profissional - Biodiversidade em Unidades de Conservação

n. 2,2020

http://www.icmbio.gov.br/revistaeletronica/index.php/BioBR

Biodiversidade Brasileira é uma publicação eletrônica científica do Instituto Chico Mendes de

Conservação da Biodiversidade (ICMBio) que tem como objetivo fomentar a discussão e a disseminação de experiências em conservação e manejo, com foco em unidades de conservação e espécies ameaçadas.

ISSN: 2236-2886 